\title{
The importance of a feminist analysis within globalization: A closer look at the global apparel industry
}

\section{Elizabeth Homer}

Department of International Development and Geography, University of Guelph, Guelph, ON Canada.

Faculty supervisor: Dr. Roberta Hawkins.For correspondence, please email: ehomer@uoguelph.ca; rhawkins@uoguelph.ca .

\section{Abstract}

Within academic literature on globalization, economic frameworks are often the dominant paradigm. Consequently, the phenomenon has been often been exclusively understood from a monetary perspective, rather than exploring its relationship with culture and geography. This paper presents an argument for the inclusion of critical feminist frameworks when studying globalization, by exposing what has been left out and encouraging what needs to be explored. As a entry point for discussing such a broad global contingency, the global apparel industry is primarily focused on; both for it's rapid expansion as a result of globalization and its obvious gendered nature, as more women than men are employed globally along the chain, and are targeted as consumers. The result is a closer look at the complex relationship between globalization, gender, race and culture. This paper is meant as a taking off point for further research within these parameters and to reinforce the importance of gender studies and critical feminist frameworks.

Keywords: Globalization; gender; global apparel industry; feminist frameworks.

\section{Introduction}

The term globalization represents a diverse range of processes and thus a singular definition has yet to be achieved. However, most academics agree that it represents an increasing economic interdependency between nations throughout the world. Cynthia Enloe (2007) acknowledges that globalization is not only limited to the expansion of capitalist business organizations; "globalization can happen to anything, not just to profit seeking companies and their employees," (Enloe, 2007). Nagar, Lawson, McDowell and Hanson (2002) argue that globalization is equivalent to global capitalism, and that is not an independent entity but a result of constructed discourses. Regardless of the precise parameters surrounding it's definition, both Enloe (2007) and Nagar et al (2002), discuss the need to expand the narrow foci within the current literature on globalization. Nagar et al (2002) argue that "contemporary globalization is intimately tied to gendered and racialized systems of oppression," and including the experiences of women is integral to understanding the dynamics of capitalism in a global context. They stress the importance of using a wide variety of scales of analysis, including the scale of the body, as a site for understanding and illustrating the interaction of gender and globalization (Nagar et al, 2002). Enloe (2007) describes that posing a feminist curiosity through inquisitiveness and concern makes visible ideas and problems that were previously hidden. She writes, "something becomes an 'issue' only when a lot of people do two things: first they start questioning it and stop taking it for granted and second, they believe it deserves public attention and public resolution," (Enloe, 2007:9)

I seek to use both the feminist curiosity described by Enloe (2007) and the critical analyses of Nagar et al (2002) to explore the often overlooked connections between gender and globalization, focusing specifically on the global apparel industry. I will use a feminist lens to illustrate what is commonly avoided and hidden within contemporary literature on globalization. I will focus on the global apparel industry because of its rapid expansion with the last two decades, making it a suitable vehicle to analyze the costs and benefits of economic globalization, and also as a place where culture, geography and the economy visibly interact. I will begin by critically analyzing an example of contemporary literature on globalization to expose the consequences of not including feminist analysis. I will also analyze a piece of literature on globalization that does include feminist perspectives to reveal how knowledge on globalization is enriched when such a framework is engaged with. Next I will focus on an alternative scale of the analysis, the body, to explore globalization from a smaller scope, revealing the intimate relationship between economic and cultural processes. Lastly, I will briefly look into fashion and the false dichotomy between producers and consumers. My 
conclusion reiterates the main themes from the paper and suggests paths for future.

\section{Women, Labour and Globalization}

\section{What is Missing}

Globalization has increased the number of women in the paid work force throughout the world, and has created and expanded economic processes such as outsourcing, informalization and off-shoring (Gottfried, 2013). Outsourcing and offshoring are both facets of economic globalization that should be subject to closer scrutiny, but are not discussed in this paper. Informalization within an economy is understood as the lack of regulation and protection of workers, resulting in vulnerability, and usually insecure work conditions with little or sometimes no pay at all (Dedeoglu, 2010). Globalization has also increased connections between, "work processes and workers through commodity chains, and intensifies these linkages across geographic spaces," (Gottfried, 2013:212). Commodity chains as defined by Leslie (2012), "connect all activities associated with the production of one good or service, such as manufacturing, consumption, design, retailing, marketing and advertising," (65). Dominant literature within globalization often avoids discussion of the consequences of the rapid increase and expansion of global commodity chains. This is largely because economic frameworks have been dominant and privilege discussion of economic growth opportunities over issues such as health, cultural and political circumstances of nations. Conversely, Nagar et al (2002) argue, "we see informal spheres as key sites for understanding globalization processes... it is precisely these spheres and activities that underwrite and actively constitute the public spheres of globalization," (260). Continuing with this idea, I begin by critically looking at a current example of literature that engages with globalization from an economic perspective.

Bangladesh is a country where the garment industry has expanded rapidly following trade liberalization policies of the 1980s. Kabeer and Mahmud (2004) attempt to prove that globalization may be a path to halve poverty in the countryside, which is one of the Millennium Development Goals. They argue, "[liberalization policies] have changed the face of female employment," (Kabeer and Mahmud, 2004:95). To prove employment opportunities generated through globalization processes can reduce poverty, they create a study that separates workers into four categories: export processing zone (EPZ) workers outside Dhaka, workers outside the EPZ in the city of Dhaka, self employed workers and other waged workers (Kabeer and Mahmud, 2004). They find that the category of Export Processing Zone workers (EPZ) had little effect on poverty in Bangladesh because they came from "considerably more educated... and more prosperous families than does the rest of the industry," and therefore, dismiss them as influence on reducing poverty. (Kabeer \& Mahmud, 2004:107). However, they conclude that women from the other sectors, including the domestic market as well as in the city of Dhaka itself, "have directly benefitted from the poorer sections of the rural population" (Kabeer \& Mahmud, 2004).

This particular study by Kabeer and Mahmud focused on poverty from fiscal perspective, disregarding the many other determinants of poverty. By not incorporating a feminist framework into their analysis, aspects of women's lives, other than finance, were not included, such as women's political participation, family life and workplace experiences. Kabeer and Mahmud (2004) concluded that EPZ workers, whom were the best off in the study, only account for approximately $12 \%$ of employment within the garment industry (Kabeer and Mahmud, 2004). Therefore, majority of women workers are still exposed to poor working conditions, low pay, and perpetual undervaluation of their paid and unpaid work. However, many of the women working outside of the EPZ cited that the biggest benefit of working within the garment industry has been "economic self reliance," and "bearing own expenses," (Kabeer \& Mahmud, 2004). Employment within the garment industry in Bangladesh has allowed women the ability to save, spend, and invest their incomes (Khosia, 2009). The feminist framework would not refuse these conclusions that women have more economic capabilities with the rise of globalization and the ready-made garment industry, but they would argue for a more enriched critical analysis of all aspects of women's lives, not only the financial. Furthermore, feminist analysis would delve further into other dimensions that define poverty, not simply income. Chant (2008) on her paper on the 'feminization of poverty' argues that it is important to pay attention to differences among women when discussing poverty, such as age, as women may be discriminated against on this basis. Additionally, understanding poverty as only income based ignores the occurrence of many women who do not have control or accessibility to money within their households (Chant, 2008). Essentially, there is a connection between poverty and power that feminist frameworks privilege when discussing globalization and/or poverty.

Kabeer and Mahmud (2004) discussed that work opportunities are now available for women where they have been previously marginalized and excluded. However, they also mention that there is a very high turnover for these women in the garment industry, and it is often seen as only a temporary form of employment (Kabeer \& Mahmud, 2004). Kabeer and Mahmud (2004) discovered in their research that most women participated in the garment industry work force less than five years; this renders any sort of economic independence, and financial contribution to their families quite precarious. Similar to these findings are those of Wright's (2006) on her study of Mexican Maquiladoras. Wright (2006) paid close attention the discourse surrounding women as "untrainable" which was then used justifiably used for rapid replacement of female workers. This was also tightly connected to race, which will be discussed in more depth later in the paper. Although Kabeer and Mahmud (2004) are not representative of all of the literature 
surrounding women's labour and globalization, their conclusions, namely that feminized labour in Bangladesh has a high likelihood of combating poverty, are problematic. Not only was poverty measured only through financial means, the lack of job security and high turnover rate that these women experience was not taken into consideration. Feminist frameworks add multidimensionality and power to the conversations about globalization, including the useful multidirectional impacts and flows, both negative and positive, and looking at 'informal' places (households) as well as 'formal' spaces.

\section{The Feminist Contribution}

Women still make significantly less money than men everywhere around the world, and it is commonly normalized and trivialized within the literature on globalization. It is as equally important to critically question and problematize the issue of gender-wage gaps, as it is to discuss the potential benefits of economic globalization. Ver Beek (2001) discusses the situation of offshore assembly workers, Maquiladoras, which arose as a result of globalization. He specifically studied Honduran Maquiladoras and concluded that male applicants and workers earn more than females of equal age and status for every position, and only men occupy the highest paying job: machine operator technician. He attributes this wage discrimination to a possible of three options: men may work faster, women may be discriminated against and there could be sampling bias; he elaborates on none of these issues, (Ver Beek, 2001). Although wage disparities are well known and documented, they are glossed over for looking at 'bigger' or more economically important issues. A more recent study by Dedeoglu (2010) reported similar conclusions regarding the hand-made garment industry in Istanbul, Turkey, where women are paid less than men because men are considered to take on more difficult skill requiring tasks. A testimony from one of the many women she interviewed reveals that the managers teach many of the female factory workers that tasks men do are simply too difficult for women; she explains they do this to, “....justify the higher wages they pay to men in the workshops," (Dedeoglu, 2010: 20). Another one of the female interviewees argues that the work isn't more difficult for women, but they believed for many years that it was (Dedeoglu, 2010).

The informal garment industry within Turkey, among many other places, as a result of global economic restructuring has succeeded in instrumentally utilizing women to expand their economy. Dedeoglu (2010) utilizes a feminist framework to draw out some of the consequences of globalization that the literature often avoids. Underlying Turkey's garment export success "is a network of subcontractors who help reduce fixed costs and provide lower labour costs," (Dedeoglu, 2010:9). This includes both home based and workshop labourers, which provide backwards linkages to factory production (Dedeoglu, 2010).
Dedeoglu (2010) states, "through subcontracting, the industry can reach untapped sources of low wage women and children," (9). She argues that "underlying the global informalization trend is the search for lower labour costs by multinational corporations..." (Dedeoglu, 2010:4). Although it can be argued that this economic restructuring has mostly benefitted women due to the large increase of women in the labour force, as Kabeer and Mahmud (2004) argued within Bangladesh, there are many gaps in such analysis. Families, communities and, most exhaustively, women, are foundational to the success of Turkey's recent economic boom. Instead of concluding that women are better off by only focusing on a economic scale of analysis, digging deeper and asking questions about disparities and informal scales of analysis reveal connections between culture and the economy, globally and locally.

Labour has become increasingly feminized in Turkey, yet women's social status still suffers. Women's home-based garment work combined with traditional housewifery and motherhood, has merged to simply represent women's labour as an expansion of their identity as "good and hard-working Muslim women," (Deodeoglu, 2010:6). This reveals an important influence of globalization on women's gender identity, social role within society, and relationship to their families. Women who participate in home-based garment work continue to provide low cost labour for the apparel industry, while simultaneously experiencing a systematic devaluation of their work (Dedeoglu, 2010). Much of their labour, paid or otherwise, is hidden to avoid public and private recognition of their work, or simply invisible and trivialized (Dedeoglu, 2010). Women often take on the role of 'good housewife' before 'paid worker' to avoid competing financially with their husbands, and posing a potential threat (Dedeoglu, 2010). As well, women's physical mobility in Turkey is still often constrained, deterring them from using public transit and work away from home (Dedeoglu, 2010). Specific shuttle busses have been created for this purpose, yet discursively the same messages of women not belonging in the 'public sphere' are reinstated. Feminist geographer Isabel Dyck (2005) discusses how important care is in formation of the global political economy. She argues, "for it is from home that social and economic life is orchestrated and, in tandem, political economies are supported." (Dyck, 2005). Essentially, using informal spaces (households) as an entry point reveals the ways in which women have been burdened by globalization instead of empowered. It is important to note that globalization should be assessed from a holistic perspective; women's social and political status and unpaid work need be discussed with the same importance as economic growth, as it is the backbone of the economic system.

The phenomenon of globalization remains uneven, "in both investments made and the kind of labour employed," (Gottfried, 2013: 207). Women's labour is simultaneously exploited for economic growth and depreciated, while often their social role is only marginally improved, if at all. Using 
the critical feminist lens discussed by both Nagar et al (2002) and Enloe (2007), it is possible to reveal and unpack issues that are often overlooked, but are often foundational to economic globalization. The conclusions one draws from the relationship between gender and globalization is informed by their perspective on the world, but what is needed regardless, is more critical analyses on the influences, consequences and connections between the global apparel industry, globalization and women's lives. My discussion of globalization and gender within this paper is contains a variety of geographically specific locations and is not necessarily sensitive to all cultural and historical particularities of the different groups of women that they were based off. They are meant to be a starting point to understanding more deeply the consequences of, and relationships women have with globalization, and provoke discussion and analysis of globalization from alternative scales. Similarly, this paper is not meant to represent globalization as only negative, or women are only victims of globalization, but rather engage critically with the relationship between women and globalization, and privilege the feminist framework as it has often been marginalized.

\section{The Body as a Scale for Analysis}

In the previous sections I outlined some social and material implications of globalization on certain groups of women participating in the global apparel industry. For this section I explore production and consumption within the global apparel industry through the scale of the body as an introduction to an alternative scale of analysis that is commonly left out of literature on globalization. Leslie (2012) argues, "a feminist analysis is sensitive to the mutually constitutive link between production and consumption, the material and the symbolic," and additionally, "explores the intersection of class, gender, race, sexuality and nationality," (68). By using the body as a scale of analysis, dialogue surrounding the gendered consequences of the global apparel chain can be opened up. Nagar et al (2002) argue for the importance of being suspicious of dualisms and binaries that arise as a consequence of globalization, which are most often inscribed into women's bodies. They also argue for research about the ways in which globalization "both connects women in networks across varied spaces and plays on and reconstitutes differences among them, as well as inequalities between women and men," (Nagar et al, 2002:260). Using a feminist framework reveals the ways women are connected along commodity chains, through spaces of subordination and devalorization.

When the scale of the body is analyzed, it is possible to see discursive consequences of globalization. Melissa Wright (2001) studied Maquiladora workers in Mexico and analyzed the ways in which women's bodies come in contact with the politics and culture of globalization. Firstly, she argues the production processes along commodity chains break down workers bodies into distinctive dualistic parts such as, male/female, first world/third world and Mexican and American (Wright, 2001). She reveals the intersection of gender, race and globalization through bodies within these factories, and the reality of these constructed dualisms. For her, a body is something that is "both produced in the imaginary realm as well as something that is productive within the materialist networks of global capital" (Wright, 2001:49). The Maquiladora factories and workers Wright (2001) researched illustrate both the subordinated and foundational position women's bodies play within globalization. She argues "the gendered divisions along the line reflect and support a discursive process which the female body emerges as an inflexible limit...Her anatomical parts are rearranged and assessed in relation to the needs of a factory system that does indeed require skilled work from her but that does not give her the credit for this skill," (Wright, 2006:52).

Therefore, women are quintessential to the processes at work within globalization, including production within the global apparel industry among other industries, yet are consistently and systemically treated as disposable. The disposability comes from the ability to pick and choose which parts of the body are useful and which ones are not, depending on what needs are to be met within the factory. Consequently, women must comply because this process is normalized and new work opportunities are highly valued. This type of analysis is rarely included within literature on economic globalization, but reflects a reality for women working within globalized factories.

When women's bodies are compartmentalized and constructed as disposable, it results in real life consequences for all female factory workers. Wright (2001) notes that male Maquiladora workers believe women don no want to move up in the company, and that they are physically un-trainable to do so, despite being good with their hands. Many managerial men explicitly believe women do not have the ability to envision themselves moving up within the company (Wright, 2001). Wright (2001) compares women's role within Maquiladoras and their bodies to "the stubborn presence of an old, mass production system even as she is integrated into the new, flexible one," (55). As a result, the ideas surrounding women's bodies as less capable are consistently normalized and maintain the women's lower status within these factories. These ideas are also tightly connected to race.

Feminist approaches to commodity chains are sensitive to intersections of gender, race, sexuality, but are also critical of the way narratives This includes recent literature on globalization, which naturalizes and trivializes racialized constructions of difference, and reproduces binaries between men and women, and third and first world women (Leslie, 2012). Something that is particularly controversial and interesting about Wright's work regarding women Maquiladora workers is the connection she draws between how American bodies are seen as more developed and Mexican bodies as less developed (Wright, 2001). When globalization interacts with gendered bodies, it is only some 
who are privileged over others. Wright (2001) explains that Mexican women are subdued to spaces of "inevitable disposability and marginality" (123), and the typical Mexican woman is considered to be docile, submissive and tradition-bound (124). Bodies of Mexican women are critically assessed on the basis of hairstyle, clothing and make up by their managers (Wright, 2001). Wright notes that at the time of her research, 3 out of 4 of the female managers at one Maquiladora identified themselves as AmericanMexican. Therefore, only those who can identify themselves as part American are seen as capable, and more likely to advance to one of the few managerial positions that women hold.

Other critical feminist authors writing about globalization have looked at the relationship between women's bodies, globalization and sexualization of work. Salzinger (2001) argues, "Gender is indeed a significant aspect of globalization, but it is the rhetoric of femininity, rather than the presence of flesh-and-blood women that enables low-cost production," (Salzinger (2001:14). She also notes that the rhetoric of productive femininity has meaning within all shop floors, but had distinctly different manifestations throughout specific Maquiladoras. She describes the factory, Panoptimex, in which femininity was so disciplined that many women were policed into specific beauty standards and made to fit in. Consequently, there are elements of surveillance, both from each other and from oneself to comply with beauty norms, as well as covert coercion techniques through the use of gossip within the factory. Both managerial men and many of the young women that work in Panoptimex factory participate in the sexualization of the line workers, and the factory itself deliberately ensured $80 \%$ of workers remain women, even when it meant bringing them in from a rural area forty-five minutes away (Salzinger, 2001). Women's bodies are used for specific repetitive work, but also for 'entertainment', and are constantly subject to objectification within this particular factory. This type of sexualization of work is not only inherent to factories that have arisen out of globalization. However, it is something that has manifested when culture and economic processes have met, and it is worthy of noting from a feminist perspective. Discursive readings of globalization reveal similarities between women positioned within global factories throughout the world. The discourse within this particular factory studied by Salzinger (2001) shaped disciplined, feminine workers.

\section{Fashion, Bodies and the Consumer/Producer Dichotomy}

The last section of this paper speaks exclusively to apparel, and the way gender interacts along the chain. Leslie (2012) argues that the temporality of fashion, "lends itself to a greater sexualization of work," (70). She adds, "Vulnerability in the workplace is related to the very product that is being manufactured. By this she is referring to fast fashion, the speed at which fashion is distributed has increased over the years resulting in, "additional pressure on suppliers to seek out a more flexible workforce," (Leslie, 2012: 70). Consequently, vulnerability spreads throughout the commodity chain and increased flexibility results in increased casual work with low no benefits (Leslie, 2012). Leslie discusses the retail chain American Apparel that is located in various places in North America and Europe. She writes, "the retail spaces are adorned with pornographic imagery," and she notes that the company's owner has been charged with sexual assault multiple times (Leslie, 2012:71). Global apparel industries located in both the global north and global south may represent places of subordination and sexualization of women; economic globalization has often flourished off of these consequences. Additionally, women are connected in spaces of oppression, undervaluation and objectification within production and retail work in the apparel industry.

Utilizing a feminist geography lens when analyzing consumption and production of garments internationally assists to reveal multi-directional flows, and dualistic constructions of difference that are left out of current analyses on globalization. Kothari and Laurie (2005) argue that the clothing industry is particularly good for illustrating the effect of the local on the global consumers and producers in the margins and directions of flows internationally. They note it is one of the oldest global industries, "and has played a part in the expansion and continuation of colonialism," (Kothari \& Laurie, 2005:224). Kothari and Laurie (2005) offer a critical and insightful analysis on the direction of flows from the supposed 'third world' to 'first world' and how clothing, bodies, consumption and production are all tightly intertwined. They believe that current literature on globalization consistently frames the core as the west, and the periphery as the third world. Furthermore, they challenge the notion of the 'third world producer' and 'first world consumer' of fashion (Kothari \& Laurie, 2005). Fashion and apparel are a significant place of study because as an industry, stylized images of so-called western fashion are created and are then globalized through multiple types of flows, including the media (Kothari \& Laurie, 2005). In the literature on globalization, there is still the tendency to speak in dualisms regarding the first and third world, and homogenize women and men within these categories. Kothari and Laurie (2005) attempt to disrupt this dualism by focusing on the different directions flows can travel, and the mutual constitution between the local and the global. Clothing not only informs representations of gendered and raced bodies, but it can reflect economic advantage and disadvantage.

Some of the discursive effects of globalization within the global apparel industry have been the construction of difference between 'third world producer' and 'first world consumer'. It can seem very imperialistic to assume all fashion is merely reflective of trends that are set in the global north that only fit certain body types and beauty standards. 
Kothari and Laurie (2005) note that "third world consumers also locate themselves in the world through clothes they wear and the goods they buy," (225). The question they ask is, what happens when 'other' bodies dress themselves in the same clothes? There appears to be a complex interaction of culture, symbolism, globalization and gender identity. Kothari and Laurie (2005) often discuss resistance to western fashion and trends in the global south. Interest in purchasing local brands is largely swayed by the global market and the power and privilege of western brands names in which, "identities, status, lifestyle and notions of modernity are constructed and displayed," (Kothari \& Laurie, 2005: 225). There is a highly uneven global economic environment, which makes it difficult to understand the meanings behind local consumption of global goods. What needs to be further challenged and discussed is the ways in which fashion, bodies and, consumption occur in the global south, which is predominantly represented only as a site of production within literature on globalization.

There is still much room for research within the global apparel industry and gender and globalization in general. Much more can be done to understand the conditions women face internationally, while working along global commodity chains. Similarly, consumption and production need to be researched together, to understand the relationship between gender and globalization. When we begin to move beyond the privileging of the economic focus to analyze globalization, alternative frameworks can be applied that assist to reveal the connections between the global north and global south, and understandings of how these categories themselves are mutually constituted. Lastly, using a feminist lens, more research can be done to understand the manifestations of the interaction between global capitalism and patriarchy, including case studies on fashion and gender, focusing on a variety of geographical contexts. Within this, sites of resistance and exploitation can be further delved into, and more pressure can be put on larger institutions and geographic regions to be accountable for mistreatment of women.

\section{Conclusion}

This paper revealed the importance of incorporating a feminist lens when analyzing globalization by focusing on the connections between gender and the global apparel industry. The use of a critical feminist lens is crucial to revealing aspects of globalization that are constantly left out of the current literature. Exploring women's material realities within the global apparel industry in such countries as Turkey and Bangladesh revealed the fundamental importance of using a feminist curiosity and a critical lens by exploring the results when it is and isn't employed. The result of using a feminist lens was a better understanding of how deeply intertwined culture and economy are, and how women's bodies and labour are the foundation of the rapid expansion of the global apparel industry. Using alternative scales to analyze commodity chains, such as bodies, assist to deepen our understanding of the way women are treated within globalized factories and the fashion industry, allowing for insight into the ways bodies, gender and globalization interact. Similarly, sensitivity to dualisms and constructions of difference stimulates new and important dialogue around the relationship between consumption and 'third world' bodies. Slowly, with a commitment to the feminist curiosity, understandings and change can occur.

\section{References:}

Burns LH, Thorpe G. 1989. Fears and phobias. Journal of Chant, Sylvia. (2008). The 'Feminisation of Poverty' and the 'Feminisation' of Anti-Poverty Programmes: Room for Revision? The Journal of Development Studies, 44(2), 165-197.

Dedeoglu, Saniye. (2010). Visible Hands-Invisible Women: Garment Production in Turkey. Feminist Economics, 16(4), 1-32.

Dyck, Isabel. (2005). Feminist geography, the 'everyday', and the local-global relations: hidden spaces of place making. The Canadian Geographer, 49(3), 233-243.

Enloe, Cynthia H. (2007). Globalization and Militarism: feminists make the link. USA: Rowman \& Littlefield Publishers Inc.

Gottfried, Heidi. (2013). Gender, Work and Economy: Unpacking the Global Economy. Cambridge, UK: Polity Press.

Kabeer, Naila., Mahmud, Simeen. (2004). Globalization, Gender and Poverty: Bangladeshi Women Workers in Export and Local Markets. Journal of International Development, 16, 93-109.

Khosia, N. (2013). The ready-made garments industry in bangladesh: A means to reducing gender-based social exclusion of women? Journal of International Women's Studies, 11(1), 289-303.

Kothari, Uma., Laurie, Nina., (2005). Different bodies, same clothes: an agenda for local consumption and global identities. Area, 37(2), 223-227.

Leslie, Deborah. (2012). Gender, Commodity Chains and Everyday Life. In Warf, B. (Eds.), Encounters and engagements between economic and cultural geography (65-78). Dordrecht, New York: Springer.

McRobbie, Angela. (1997). Bridging the Gap: Feminism, Fashion and Consumption. Feminist Review, (55), 7389.

Nagar, Richa., Lawson, Victoria., McDowell, Linda., Hanson, Susan., (2002). Locating Feminist (Re)readings of the Subjects and Spaces of Globalization. Economic Geography, 78 (3), 257-284. 
Salzinger, L. (2001). Making fantasies real: Producing women and men on the Maquila shop floor. NACLA Report on the Americas, 34, 13-19.

Ver Beek, Kurt Alan. (2001). Maquiladoras: Exploitation or Emancipation? An Overview of the Situation of Maquiladora Workers in Honduras. World Development, 29(9), 1553-1567.

Wright, Melissa W. (2006). Disposable Women and Other Myths of Global Capitalism. NewYork, NY: Taylor \& Francis Group 